\section{Dendritic Cells: Biology and Clinical Applications}

\author{
Edited by Michael T. Lotze \& \\ Angus W. Thomson \\ Academic Press, \$149.95, 733 pp. \\ ISBN: 0124558607, 1999
}

\author{
Hidde L. Ploegh \\ Department of Pathology \\ Harvard Medical School \\ 200 Longwood Ave \\ Boston, Massachusetts 02115
}

Immunologists and cell biologists have been increasingly preoccupied with dendritic cells (DCs) over the past decade. DCs occur in different manifestations: interdigitating cells, follicular dendritic cells, lymphoid dendritic cells, many of them with subsets defined according to anatomical site, maturation or activation status. These cells, whose discovery dates back to the late 1960s-early 1970s, are now seen as a panacea for vaccine development, tumor immunotherapy and a host of other immunological applications. In particular, the vastly improved methods for their isolation and propagation in tissue culture, as well as more refined tools for phenotyping through surface markers, have greatly advanced the field. No reader of the immunological literature can plead ignorance: almost every issue of every major journal continues to report progress in our unraveling of the DC's unique and important function. At the same time, the ability to obtain reasonably pure populations of cells in tissue culture has allowed cell biologists and biochemists to make inroads in the ever more intricate pathways of antigen presentation. How do DCs load their MHC class II molecules with peptide cargo ? How do DCs process the remnants of apoptotic cells?

This book, edited by Lotze and Thomson, has as its stated goal the bringing together of information that would allow a clinician or a non-immunologically oriented scientist to appreciate the role of DCs. I am deeply sympathetic to the editors' unenviable task of herding their flock: no fewer than 123 authors have contributed to 39 chapters in approximately $1.5 \mathrm{~kg}$ (more than 700 pages) of text. The expert will recognize the leaders in the field among the con- tributors, and clearly much recent information can be obtained through the text as well as through the reference lists at the end of each chapter. There is considerable heterogeneity in how the authors acquitted themselves of the task before them: some chapters are a few pages long and mostly self-referential, others provide more comprehensive reviews. As Steinman and Banchereau state in the introduction, it is increasingly more difficult for scientists to write these chapters (and

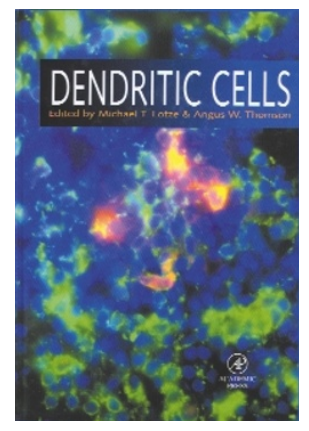

would help the hapless clinician or nonimmunologist. This opportunity was missed in the omission of a chapter providing an overview of DC heterogeneity. Such a chapter would likewise include not only a description of the marker profiles commonly used (this may be found in the numerous, often redundant tables interspersed in the text), but would also explain what these markers stand for. Equally helpful would have been a concordance that would attempt to re-interpret for some of them, it shows, I might add: deadlines, deadlines).

The book is organized into six sections: origins of DCs, DCs in the periphery, DCs interacting with other cells, DC in disease, DC-based therapies, and a final section that deals with techniques and sundry topics in DC biology. I was particularly impressed with the chapters on DC in the central nervous system (by McMenamin and Forrester), DCs in autoimmunity (by Drexhage et al.) and a succinct and well-illustrated treatment of DC in allergy (by Semper et al.). The techniques section wouldn't get anyone in the laboratory started on the culture and propagation of DCs, or anything else for that matter (no protocols or recipes), but would at least tell them where to look for such information. All in all, the reader most certainly gets a good sense of the breadth of this now mature field of immunological exploration.

However, the book falls short of the mark in providing the introduction that

\section{Judging Science: Scientific Knowledge and the Federal Courts} and reconcile the older nomenclature and histological descriptions of DCs with the currently accepted standards.

A few minor issues remain. One might perhaps quibble with the historically revisionist introduction by the editors: who did discover dendritic cells? And what about the earlier studies of, for example, Nossal on follicular dendritic cells? What about the admittedly obscure publication by Veldman in 1970 on interdigitating (dendritic) cells? I would have appreciated also consistency in referencing (alphabetical for most chapters, numbered for others). Some of the color figures, found as a 32-page 'block' in the middle of the book, are clearly functional (micrographs, histochemistry), whereas others might as well have been reproduced in black-andwhite only. My conclusion: for those who already know how to navigate the field, this book is a useful compendium, but for the nonspecialist, this book is not the place to start.

neous disdain and fear of juries composed of these same potential customers, also known as average citizens. Perhaps most frightening is the thought that juries will be persuaded by trial lawyers and phony epidemiologists that their product causes injury.

Judging Science is the second book on epidemiology in the courtroom these authors have produced with the support of the conservative Manhattan Institute for Policy Research. The Manhattan Institute describes itself as trying to shape "American political culture" with "market-oriented policies" and touts promoting their books-which they make "every effort to ensure" are published "by respected trade publishers"—as "central to our approach." 